\title{
Optical Properties of Chiral Azo-Schiff Base Mn(II) and Zn(II) Complexes with Silver Nanoparticles
}

\author{
Kazuya Saiga ${ }^{1}$, Tomoyuki Haraguchi ${ }^{1}$, Yasutaka Kitahama ${ }^{2}$, Takuya Hosokai², \\ Hiroyuki Matsuzaki², Dohyun Moon ${ }^{3}$, Mutsumi Sugiyama', Michikazu Hara ${ }^{5}$, Takashiro Akitsu ${ }^{*}$ \\ ${ }^{1}$ Department of Chemistry, Faculty of Science, Tokyo University of Science, Tokyo, Japan \\ ${ }^{2}$ National Institute of Advanced Industrial Science and Technology, Tsukuba, Japan \\ ${ }^{3}$ Pohang Accelerator Laboratory, Pohang, Korea \\ ${ }^{4}$ Department of Electrical Engineering, Faculty of Science and Technology, Tokyo University of Science, Noda, Japan \\ ${ }^{5}$ Materials and Structures Laboratory, Tokyo Institute of Technology, Yokohama, Japan \\ Email: *akitsu2@rs.tus.ac.jp
}

How to cite this paper: Saiga, K., Haraguchi, T., Kitahama, Y., Hosokai, T., Matsuzaki, H., Moon, D., Sugiyama, M., Hara, M. and Akitsu, T. (2021) Optical Properties of Chiral Azo-Schiff Base $\mathrm{Mn}(\mathrm{II})$ and Zn(II) Complexes with Silver Nanoparticles. Journal of Materials Science and Chemical Engineering, 9, 1-10.

https://doi.org/10.4236/msce.2021.94001

Received: March 9, 2021

Accepted: April 2, 2021

Published: April 9, 2021

\begin{abstract}
Herein we have originally designed chiral azo-salen $\mathrm{Mn}(\mathrm{II})$ and $\mathrm{Zn}(\mathrm{II})$ complexes for interacting silver nanoparticles (AgNPs) exhibiting localized surface plasmon resonance (LSPR). Understanding excited state and reaction intermediate during light irradiation to return to ground state may be important for such composite systems. Therefore, we investigated such optical properties for systems using time-resolved luminescence and transient absorption measurements. DMSO solutions of the four newly prepared and characterized complexes (MMn, MZn, CMn, and CZn) and ethanol solutions of the composite materials of each complex with AgNPs were served for optical measurements. The time-correlated single photon counting (TCSPC), the streak camera which is much shorter period of time than TCSPC and transient absorption measurement, was performed for the eight samples. The fluorescence lifetime of the sole complexes and the composite materials with AgNPs was derived from curve-fitting analysis of luminescence decay curves of TCSPC. Lifetime of the composite systems with AgNPs was longer than that of the corresponding sole metal complexes for three cases. It was revealed that composite systems may go through three reaction intermediates during relaxation from excited state to ground state.
\end{abstract}

\section{Keywords}

Schiff Base Metal Complexes, Azobenzene, Silver Nanoparticles, Fluorescence Lifetime 


\section{Introduction}

In recent years, we have carried out photochemical studies on chiral azo-Schiff base metal complexes as hybrid materials, for example, focusing on (with titanium oxide) cis-trans photoisomerization of azobenzene moiety [1], non-linear optical effect of chiral molecules [2], (with gold nanoparticles) induced circular dichroism (CD) as supramolecular chiroptical measurements of chiral molecules [3] [4] and polarized light control of molecular orientation on the surface resulted from induced CD due to Weigert effect of azobenzene moiety [5]. In this way, we attempted new mechanisms to improve the performance of DSSC in future. In this study, herein, we have prepared hybrid materials of new chiral azo-Schiff base $\mathrm{Mn}(\mathrm{II})$ and $\mathrm{Zn}$ (II) complexes and AgNPs (with or without titanium oxide), and investigated their photophysical and chiroptical properties. Especially, time-resolving optical measurements were employed in order to understand excited state and reaction intermediates during light irradiation to return to the ground state. Some complexes with AgNPs exhibited longer fluorescence lifetime than that sole complexes without AgNPs.

\section{Experimental}

\subsection{Materials and Methods}

Potassium hydroxide, 3,5-dichlorosalicylaldehyde were purchased from Wako Fujifilm. Manganese(II) chloride tetrahydrate, zinc(II) acetate dihydrate, aniline, sodium nitrite and sodium hydroxide were purchased from Kanto Chemical Co., Inc. Salicylaldehyde, $p$-anisidine and 4 -aminobenzoic acid were obtained from Tokyo Chemical Industry. 4,4'-((1S,2S)-1,2-diammonioethane-1,2-diyl)dibenzoate and $(2 S, 3 S)$-3-aminoaspartic acid, $(E)$-2-hydroxy-5-

((4-methoxyphenyl)diazenyl)benzaldehyde and (E)-2-hydroxy-5-

((4-carboxyphenyl)diazenyl)benzaldehyde were prepared according to the literature procedures [1] [2] [3] [4] [5]. AgNPs (30 - $80 \mathrm{~nm}$ ) were synthesized using a modified polyol method [6] [7].

\subsection{Synthesis of Metal Complexes}

Preparation schemes of the four complexes were shown in Figure 1.

\subsubsection{Synthesis of MMn}

To a methanol solution $(15 \mathrm{~mL})$ of 4,4'-((1S,2S)-1,2-diaminoethane-1,2-diyl) benzoic acid $(0.06 \mathrm{~g}, 0.2 \mathrm{mmol})$, a methanol solution $(10 \mathrm{~mL})$ of potassium hydroxide (0.1 g, $1.7 \mathrm{mmol})$ and (E)-2-hydroxy-5-((4-methoxyphenyl)diazenyl) benzaldehyde $(0.10 \mathrm{~g}, 0.4 \mathrm{mmol})$ was added, and the resultant mixture was stirred at $313 \mathrm{~K}$ for $2 \mathrm{~h}$. Then manganese(II) chloride tetrahydrate $(0.040 \mathrm{~g}, 0.2$ $\mathrm{mmol}$ ) was added, and the solution was stirred for $2 \mathrm{~h}$. After filtration, the filtrate was concentrated under reduced pressure to obtain a black solid. This solid was washed with water, methanol $(273-278 \mathrm{~K})$ and hexane to give rise to pure MMn (as potassium salt). Yield (59.7\%). Anal. Found: C, 59.51; H, 4.17; N, 9.10. 


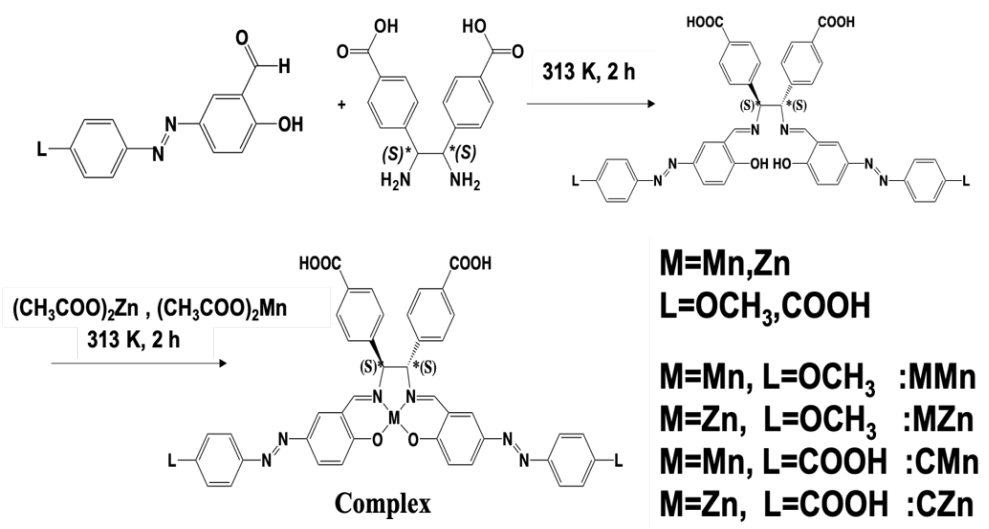

Figure 1. Preparation schemes of the complexes with abbreviation.

Calcd. for: $\mathrm{C}_{44} \mathrm{H}_{32} \mathrm{~K}_{2} \mathrm{~N}_{6} \mathrm{O}_{8} \mathrm{Mn}$ : C, 58.34; $\mathrm{H}, 3.56 ; \mathrm{N}, 9.28$. IR (KBr, cm $\left.{ }^{-1}\right), 542(\mathrm{~m})$, $722(\mathrm{w}), 790(\mathrm{w}), 837(\mathrm{~m}), 1025(\mathrm{~m}), 1115(\mathrm{~m}), 1154(\mathrm{~m}), 1182(\mathrm{w}), 1252(\mathrm{~s})$, 1299 (s), 1377 (s), 1462 (w), 1501 (m), 1541 (m), 1597 (s, C=N), 1699 (m, C=O), 3423 (br, s). TG-DTA (K) 458 (endo), 523 (decomposition). CV $\mathrm{E}_{\mathrm{ox}}=-1.340$, $\mathrm{E}_{\text {red }}=1.055 \mathrm{~V}$.

\subsubsection{Synthesis of MZn}

Pure MZn (as potassium salt) was obtained in the similar procedure to MMn using zinc(II) acetate dihydrate instead of manganese(II) chloride tetrahydrate. Yield (66.0\%). Anal. Found: C, 58.02; H, 4.13; N, 8.44. Calcd. for: $\mathrm{C}_{44} \mathrm{H}_{32} \mathrm{~K}_{2} \mathrm{~N}_{6} \mathrm{O}_{8} \mathrm{Zn}$ : C, 57.67; H, 3.52; N, 9.17. IR (KBr, cm $\left.{ }^{-1}\right), 534(\mathrm{w}), 609(\mathrm{w}), 837(\mathrm{~m}), 1030(\mathrm{~m})$, $1106(\mathrm{w}), 1180(\mathrm{w}), 1207(\mathrm{w}), 1250(\mathrm{~s}), 1297(\mathrm{w}), 1316(\mathrm{w}), 1402(\mathrm{w}), 1443(\mathrm{~m})$, 1500 (s), 1536 (w), 1597 (s), 1625 (s, C=N), 1698 (m, C=O), 3434 (br, s). TG-DTA (K) 458 (endo), 523 (decomposition). ${ }^{1} \mathrm{H}-\mathrm{NMR}$ (DMSO-d6, ppm): $\delta$ H13.94 (s, 1H), $9.09(\mathrm{~s}, 1 \mathrm{H}), 8.16(\mathrm{~d}, 1 \mathrm{H}), 7.90(1 \mathrm{H}), 7.82(\mathrm{~d}, 2 \mathrm{H}), 7.44(\mathrm{~d}, 2 \mathrm{H})$, $7.08(\mathrm{t}, 3 \mathrm{H}), 7.00(\mathrm{~d}, 2 \mathrm{H}), 3.82(\mathrm{~s}, 3 \mathrm{H}), 3.77(\mathrm{~s}, 3 \mathrm{H}) . \mathrm{CV} \mathrm{E}_{\mathrm{ox}}=-0.833, \mathrm{E}_{\text {red }}=1.037$ V.

\subsubsection{Synthesis of CMn}

To a methanol solution $(15 \mathrm{~mL})$ of $4,4^{\prime}-((1 S, 2 S)$ -

1,2-diaminoethane-1,2-diyl)dibenzoic acid (0.06 g, $0.2 \mathrm{mmol})$, methanol solution $(10 \mathrm{~mL})$ of potassium hydroxide $(0.1 \mathrm{~g}, 1.7 \mathrm{mmol})$ and

(E)-2-hydroxy-5-((4-carboxyphenyl)diazenyl)benzaldehyde $(0.108 \mathrm{~g}, 0.4 \mathrm{mmol})$ was added, and the resultant mixture was stirred at $313 \mathrm{~K}$ for $2 \mathrm{~h}$. Then manganese(II) chloride tetrahydrate $(0.0395 \mathrm{~g}, 0.2 \mathrm{mmol})$ was added, and the solution was stirred for $2 \mathrm{~h}$. After filtration, the filtrate was concentrated under reduced pressure, to obtain a black solid. This solid was washed with water, methanol $(273-278 \mathrm{~K})$ and hexane to give rise to pure $\mathrm{CMn}$. Yield (49.9\%). Anal. Found: C, 61.04; H, 3.74; N, 9.73. Calc. for: $\mathrm{C}_{44} \mathrm{H}_{30} \mathrm{~N}_{6} \mathrm{O}_{10} \mathrm{Mn}$ : C, 61.61; H, 3.53; N, 9.80. IR $\left(\mathrm{KBr}, \mathrm{cm}^{-1}\right), 525(\mathrm{w}), 838(\mathrm{~m}), 716(\mathrm{w}), 787(\mathrm{w}), 837(\mathrm{~m}), 1027(\mathrm{w}), 1111(\mathrm{w})$, $1151(w), 1181(w), 1251(s), 1307(w), 1307(w), 1378(w), 1441(w), 1501(m)$, 1544 (w), 1599 (s), 1624 (s, C=N), 1685 (s, C=O), 3407 (br, s). TG-DTA (K) 573 (decomposition). $\mathrm{CV} \mathrm{E}_{\mathrm{ox}}=-1.217, \mathrm{E}_{\mathrm{red}}=0.726 \mathrm{~V}$. 


\subsubsection{Synthesis of CZn}

Pure CZn (as potassium salt partly) was obtained in the similar procedure to CMn using zinc(II) acetate dihydrate instead of manganese(II) chloride tetrahydrate. Yield (68.9\%). Found: C, 57.48; H, 3.49; N, 8.73. Anal. Calc. for: $\mathrm{C}_{44} \mathrm{H}_{29} \mathrm{KN}_{6} \mathrm{O}_{10} \mathrm{Zn}: \mathrm{C}, 58.32 ; \mathrm{H}, 3.23 ; \mathrm{N}$, 9.27. IR $\left(\mathrm{KBr}, \mathrm{cm}^{-1}\right), 546(\mathrm{w}), 556(\mathrm{w}), 709$ (m), $783(\mathrm{~m}), 838(\mathrm{w}), 864(\mathrm{w}), 903(\mathrm{w}), 1012(\mathrm{~m}), 1110(\mathrm{~m}), 1144(\mathrm{w}), 1187(\mathrm{w})$, $1285(\mathrm{~m}), 1309$ (w), 1383 (s), $1474(\mathrm{w}), 1556(\mathrm{~m}), 1605$ (s, C=N), 1683 (s, C=O), 3434 (br, s). TG-DTA (K) 573 (decomposition). ${ }^{1} \mathrm{H}-\mathrm{NMR}$ (DMSO-d6, ppm): $\delta$ $8.41(\mathrm{~s}, 2 \mathrm{H}), 8.18(\mathrm{~d}, 1 \mathrm{H}), 8.08(\mathrm{~d}, 3 \mathrm{H}), 8.01(\mathrm{~d}, 5 \mathrm{H}), 7.89(\mathrm{t}, 7 \mathrm{H}), 7.83(\mathrm{~s}, 2 \mathrm{H})$, $7.75(\mathrm{~d}, 5 \mathrm{H}), 7.51(\mathrm{~d}, 5 \mathrm{H}), 6.80(\mathrm{~d}, 2 \mathrm{H}), 5.34(\mathrm{~s}, 2 \mathrm{H}) \mathrm{CV} . \mathrm{E}_{\mathrm{ox}}=-0.869, \mathrm{E}_{\mathrm{red}}=$ $0.713 \mathrm{~V}$.

\subsection{Physical Measurements}

Elemental analyses (C, $\mathrm{H}$ and N) were performed using a Perkin-Elmer $2400 \mathrm{II}$ CHNS/O analyzer at the Tokyo University of Science and using an Elementer vario MICRO cube at TORAY Research Center. Infrared (IR) spectra were recorded as $\mathrm{KBr}$ pellets on a JASCO FT-IR 4200 plus spectrophotometer in the range $4000-400 \mathrm{~cm}^{-1}$ at $298 \mathrm{~K}$. Electronic (UV-vis) spectra were obtained on a JASCO V-650 UV-vis-NIR spectrophotometer in the range $800-200 \mathrm{~nm}$ at 298 K. Circular dichroism (CD) spectra were obtained on a JASCO J-820 spectropolarimeter in the range $800-250 \mathrm{~nm}$ at $298 \mathrm{~K} .{ }^{1} \mathrm{H}$-NMR spectra were recorded on a JEOL JMN-300 spectrometer (300 MHz). Electrochemical (cyclic voltammetry, CV) measurement were carried out on a BAS SEC2000-UV/VIS and ALS2323 system with $\mathrm{Ag} / \mathrm{AgCl}$ electrodes range of $-2.0-1.5 \mathrm{~V}$ vs. $\mathrm{Ag} / \mathrm{Ag}^{+}$. Raman spectroscopy was recorded using JASCO NRS-3200. I - V measurement was obtained Yamashita Denso YSS-80 at $298 \mathrm{~K}$. XPS measurement was carried out using Mg $\mathrm{Ka}$ source $(10 \mathrm{kV}, 25 \mathrm{~mA})$ on a SHIMADZU ESCA3400. Powder X-ray diffraction patterns were collected at $298 \mathrm{~K}$ with Pohang Light Source II 2D Supramolecular Crystallography Beamline (PLSII-2D-SMC). Nanosecond time-resolved TA measurements were carried out with a Ti: sapphire laser (LibraHE, Coherent). The second harmonic (400 nm) of the laser was used for excitation. The intensity of the laser pulse $(70 \mathrm{~mW})$ was measured with an air-cooled thermopile sensor (PM2, Coherent). A xenon lamp (C4251, Hamamatsu) was used as the probe light source. The light transmitted through the sample was passed through monochromator (CM110, Spectral Products) and detected with a Si photodiode (DET10A/M, Thorlabs). The photocurrent from the detector was amplified with an amplifier (DHPVA-201, Femto), and signals were processed with a digital oscilloscope (WaveRunner8254, Teledyne LeCroy) and analyzed with a computer. The DC offset of the photocurrent from the detector was subtracted by using the AC-coupled mode of the amplifier. TCSPC measurements were carried out using FluoroCube (Horiba). For the excitation light source, a pulsed laser diode (Horiba, NanoLED; wavelength of $410 \mathrm{~nm}$, pulse width of $200 \mathrm{ps,} \mathrm{and} \mathrm{repetition}$ rate of $1 \mathrm{MHz}$ ) was used. For streak camera measurements, the second harmonic $(400 \mathrm{~nm})$ light of the Ti: sapphire laser (Solstice, Spectra Physics; pulse width of 
$100 \mathrm{fs}$, and repetition rate of $1 \mathrm{kHz}, 3.3 \mathrm{~mW}$ ) was irradiated to the samples and photoluminescence was corrected using C4334-01 (Hamamatsu Photonics).

\subsection{Computational Methods}

Calculations of all complexes were performed using the Gaussian 09W software Revision D.02 (Gaussian, Inc.) [8]. Starting models (four-coordinated square planar) of structural optimization is based on preliminary results of Rietveld analysis and TG-DTA. The gas phase geometry optimizations were carried out by using TD-DFT with B3LYP functional. The vertical excitation energy was calculated with the Lanl2dz for each complexes, with the $6-31+\mathrm{G}(\mathrm{d})$ basis set for $\mathrm{H}, \mathrm{C}, \mathrm{N}$ and $\mathrm{O}$ method based on the singlet ground state geometry.

\section{Results and Discussion}

\subsection{Spectral Features of Metal Complexes with/without AgNP}

For example, UV-vis spectra for MZn and AgNP appeared at 391, $450 \mathrm{~nm}$ and $270,450 \mathrm{~nm}$, respectively, whose the strongest peaks around $380 \mathrm{~nm}$ could be assigned to be p-p $\mathrm{p}^{*}$ transition of trans-form as shown in Figures 2(a)-2(d). Substitution to $\mathrm{Mn}$ (II) ion and carboxyl groups resulted in short wavenumber shift of UV-vis spectra (MZn $391>$ MMn $387>$ CZn $371>$ CMn 364 nm). The peaks shifted to long wavelength region on formation $\mathrm{MZn}+\mathrm{AgNP}$ composite (Figure 3). CD spectra for MZn appeared at 300 and $410 \mathrm{~nm}$, though induced CD could

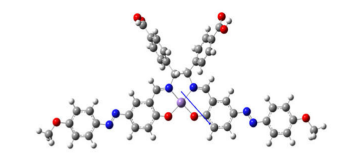

Dipole moment 4.4343

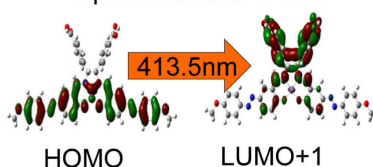

(a)

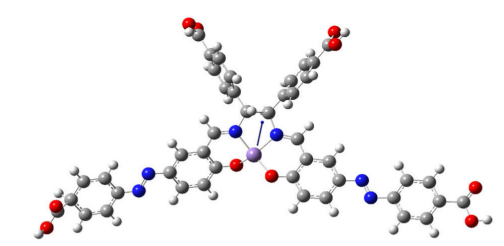

Dipole moment 3.7069

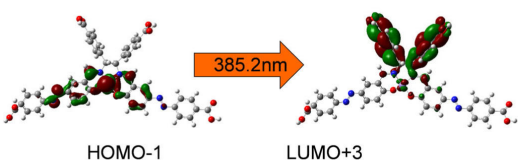

(c)

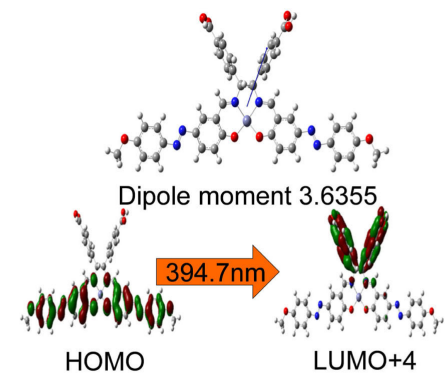

(b)

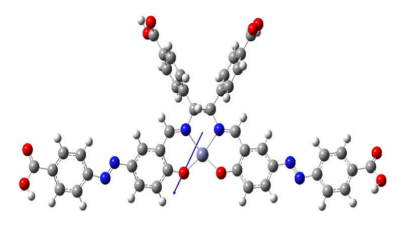

Dipole moment 2.6896

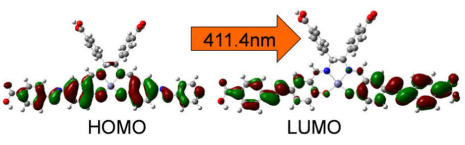

(d)

Figure 2. DFT optimized structures with dipole moment and assignment of transition of the strongest UV-Vis peaks for (a) MMn, (b) MZn, (c) CMn, and (d) CZn. 

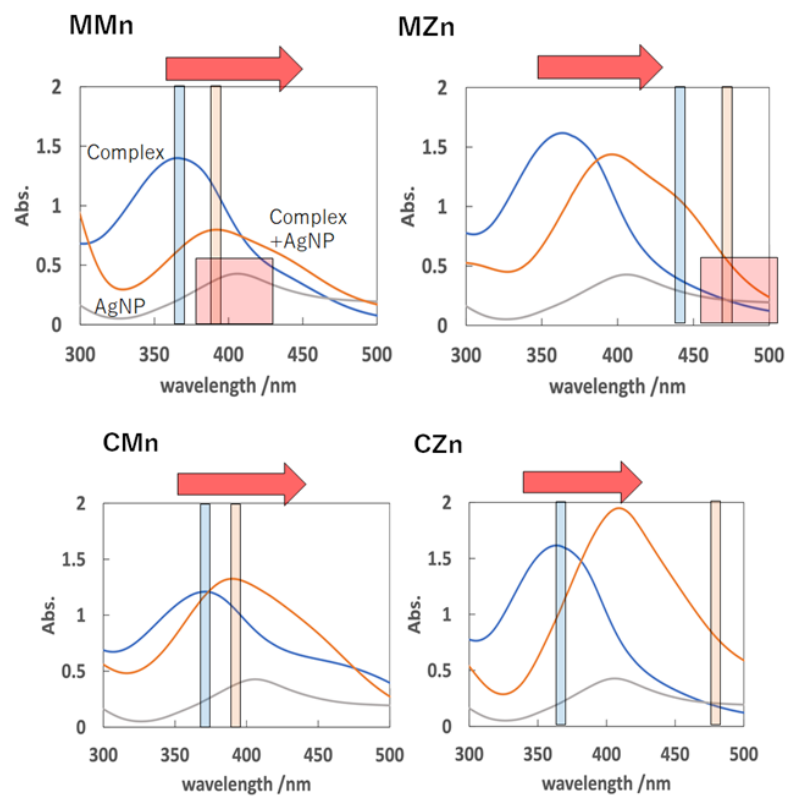

Figure 3. UV-vis spectral shift after formation AgNP composites for MMn, MZn, CMn, and CZn.

not be observed clearly for $\mathrm{MZn}+$ AgNP composite for all complexes due to unsuitable arrangement of dipole moments of chiral complex and AgNP [4] [5]. Low-energy shift of XPS also suggested adsorption of metal complexes onto AgNPs: $3 \mathrm{~d}_{5 / 2}$ and $3 \mathrm{~d}_{3 / 2}$ are 368.328 and $374.312 \mathrm{eV}$ for AgNPs, 368.159 and $374.145 \mathrm{eV}$ for MMn + AgNP, 368.157, 374.138 eV for MZn + AgNP, 368.244, $374.39 \mathrm{eV}$ for CMn + AgNP, and 368.206, 374.182 eV for CZn + AgNP, respectively. On adsorbing on AgNP, as shown in Figure 4, fluorescence spectra of carboxyl complexes (CMn and CZn) exhibited more clear quenching than that of methoxy complexes (MMn and MZn).

\subsection{Nanosecond Time-Resolved Spectroscopy of Fluorescence Decay}

Time-correlated single photon counting (TCSPC) were carried out to investigate the photoexcited state and the reaction intermediate state when each complex and its composite system (8 samples in total) were illuminated [9]. The fluorescence decay plots (Figure 5) were analyzed to obtain the fitting parameters (Table 1) to the exponential functions (1) and (2) using an ORIGIN software. It was found that this task could be achieved by compositing silver nanoparticles. The relaxation constants are faster in the order $\tau_{1}>\tau_{2}>\tau_{3} . A_{1}, A_{2}$, and $A_{3}$ are the component ratios of the respective relaxation components. The average fluorescence lifetime was calculated by the following equation.

$$
\begin{gathered}
I(t)=A_{1} \exp \left(-t / \tau_{1}\right)+A_{2} \exp \left(-t / \tau_{2}\right)+A_{3} \exp \left(-t / \tau_{3}\right) \\
t_{\text {aver }}=\left(A_{1} \tau_{1}+A_{2} \tau_{2}+A_{3} \tau_{3}\right) /\left(A_{1}+A_{2}+A_{3}\right)
\end{gathered}
$$

Only for $\mathbf{M Z n}+$ AgNP composite, $\tau_{\text {avg }}$ was longer than sole complex (MZn), which indicated that the average fluorescence lifetime of other complexes is 

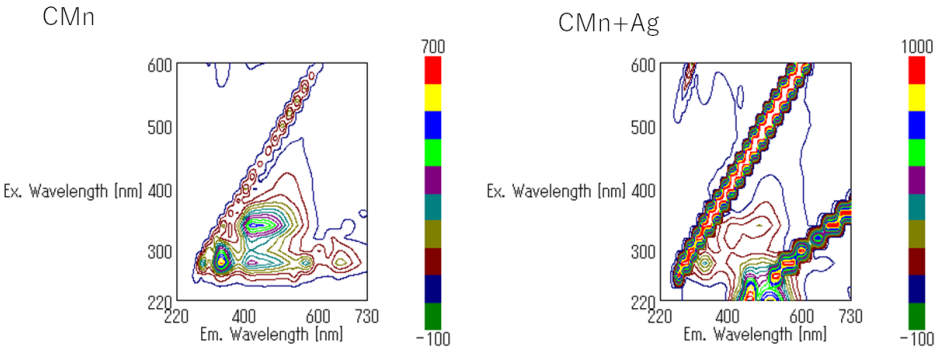

$$
\text { CZn }
$$
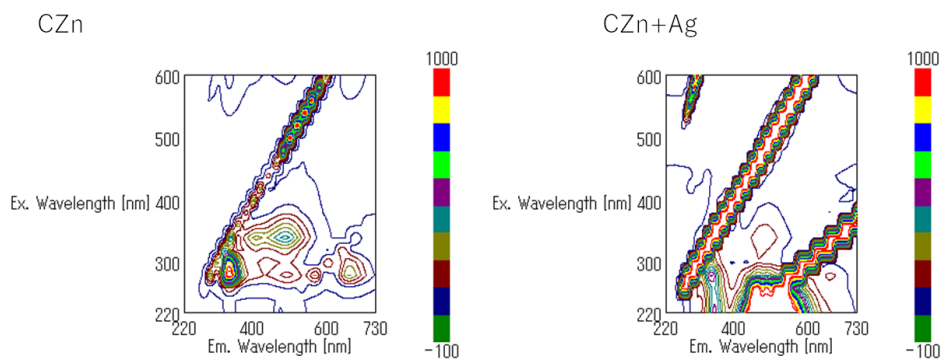

Figure 4. 3D fluorescence peaks for CMn, CMn + AgNP, CZn, and CZn + AgNP.
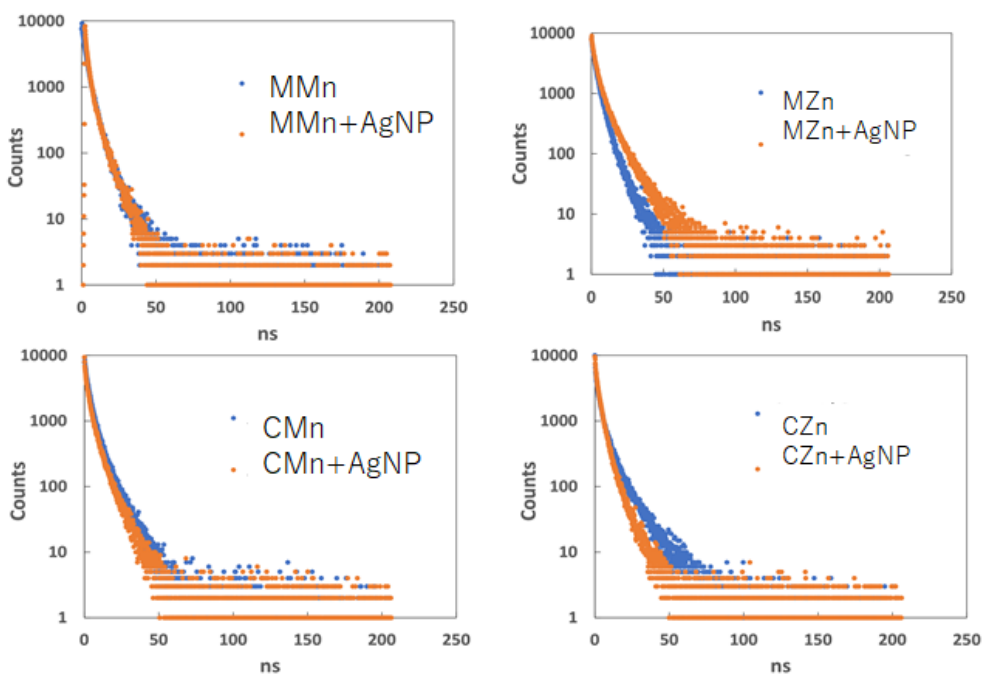

Figure 5. Fluorescence decay curves comparison with existence of AgNPs for MMn, $\mathrm{MZn}, \mathrm{CMn}$, and CZn.

Table 1. Fitting parameters for each system.

\begin{tabular}{cccccccc}
\hline samples & $A_{1}$ & $\tau_{1}(\mathrm{~ns})$ & $A_{2}$ & $\tau_{2}(\mathrm{~ns})$ & $A_{3}$ & $\tau_{3}(\mathrm{~ns})$ & $\tau_{\text {ave }}(\mathrm{ns})$ \\
\hline MMn & 3581.1 & 0.25 & 6287.4 & 2.48 & 1809.7 & 6.26 & 2.38 \\
MMn + AgNP & 5972.2 & 0.24 & 5245.6 & 1.82 & 1392.3 & 6.15 & 1.55 \\
MZn & 5438.0 & 0.20 & 4919.5 & 2.27 & 2259.1 & 5.83 & 2.01 \\
MZn + AgNP & 3625.1 & 0.28 & 5754.4 & 2.51 & 2084.4 & 8.43 & 2.88 \\
CMn & 3934.1 & 0.36 & 5768.3 & 2.64 & 1701.8 & 8.05 & 2.66 \\
CMn + AgNP & 6572.6 & 0.18 & 4834.1 & 2.09 & 1868.4 & 6.62 & 1.78 \\
CZn & 4883.9 & 0.31 & 4368.0 & 2.55 & 1141.2 & 9.36 & 2.25 \\
CZn + AgNP & 5157.3 & 0.31 & 5070.8 & 2.35 & 1604.4 & 6.10 & 1.97 \\
\hline
\end{tabular}




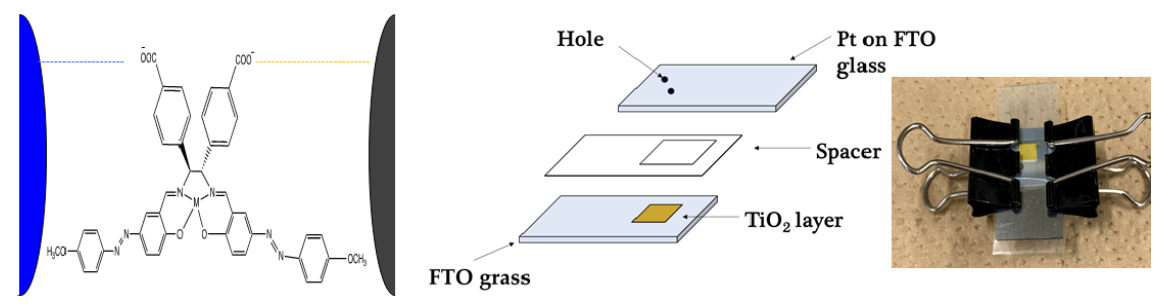

Figure 6. (Left) Proposed (the sole bridging) adsorption structure of $\mathrm{TiO}_{2}$ (blue)-MZn-AgNP (black). (Middle) The cell assembled. (Right) Appearance of the cell.

shortened by the addition of AgNPs ascribed to effective energy transfer through carboxyl groups. Due to Mn(II) ion unsuitable for excitation, MMn + AgNP composite showed the shortest $\tau_{\text {avg }}$ of $1.55 \mathrm{~ns}$. In this way, the results observed were caused by the energy coupling between the plasmon resonance and the emission of the fluorescent molecules, which shortens the electronic recombination time from the excited state to the ground state and accelerates the radiation relaxation. A previous study [9] reported that the presence of metal nanoparticles in the vicinity of fluorescent molecules shortens the fluorescence lifetime of the fluorescent molecules. This suggests that AgNP could not exist in the vicinity of the composite due to aggregation of AgNPs in MZn + AgNP. While CZn has many carboxyl groups to adsorb on AgNPs. Therefore, when AgNP were combined with the complex, the carboxyl groups of the complex were able to bind to AgNPs and maintain a close proximity.

\subsection{Application for DSSC Dyes}

Discussion in 3.2 suggests that $\mathrm{MZn}+\mathrm{AgNP}$ may be suitable for sensitizer of DSSC among the four complexes, and cells [1] assembled as Figure 6, in which adsorption of MZn to AgNP was monitored with Raman peaks at 1417 and 1042 $\mathrm{cm}^{-1}$. The DFT calculation shows that the positional relationship of the orbitals before and after excitation is in an advantageous position with respect to the adsorption substituents. Redox potentials from CV suggested that the four complex may be appropriate for sensitizer electrochemically (LUMOs are higher than $-0.540 \mathrm{~V}$ for $\mathrm{TiO}_{2}, \mathrm{HOMOs}$ are lower than $0.460 \mathrm{~V}$ for $\left.\mathrm{I}^{-} / \mathrm{I}_{3}^{-}\right)$. Photoelectric conversion efficiency could be evaluated to be $0.433 \%, 0.0377 \%$, and $0.342 \%$ for AgNP, MZn, and MZn + AgNP, respectively based on I - V curves. In contrast, employing $\mathrm{MZn}$ shorten $t_{\text {ave }}$, the corresponding values are $0.433 \%$, $0.0837 \%$, and $0.655 \%$ for AgNP, CZn, and CZn + AgNP, respectively. The results indicated that other factors associated with cells may make it inefficient besides excited state of $\mathbf{M Z n}+\mathrm{AgNP}$.

\section{Conclusion}

In this work, we evaluated the physical properties of chiral Schiff azo-salen $\mathrm{Mn}(\mathrm{II})$ and $\mathrm{Zn}$ (II) complexes and their composites with AgNPs in order to search useful dyes for DSSC. UV-vis spectra of the four complexes with AgNP exhibited longer wavelength shift than the complex solely. Finally, TCSPC mea- 
surements were carried out to compare the photo-excited states and reaction intermediate states of the complexes alone and the composite systems with AgNPs. As a result, it was found that the average fluorescence lifetime became shorter by addition of AgNPs except for MZn. This may be due to the energy coupling between the plasmon resonance and the emission of the fluorescent molecules, which reduces the electronic recombination time from the excited state to the ground state and accelerates the radiation relaxation. As described above, the changes in photo-responsivity due to the differences in the substituents and central metal of the complexes were confirmed by several spectroscopic measurements.

\section{Acknowledgements}

The synchrotron X-ray crystallography experiment at PLS-II BL2D-SMC beamline was supported in part by MSICT and POSTECH. This work was supported by microstructural characterization platform as a program of "Nanotechnology Platform" of the Ministry of Education, Culture, Sports, Science and Technology (MEXT), Japan, Grant Number JPMXP09A20AT0016 and JPMXP09A20AT0060. This work was partly supported by the Collaborative Research Project of Laboratory for Materials and Structures, Institute of Innovative Research, Tokyo Institute of Technology.

\section{Conflicts of Interest}

The authors declare no conflicts of interest regarding the publication of this paper.

\section{References}

[1] Tanaka, S., Sato, H., Ishida, Y., Deng, Y., Haraguchi, T., Akitsu, T., Sugiyama, M., Hara, M. and Moon, D. (2018) Photo-Control of Adsorption of Dye Metal Complexes Incorporating Chiral Schiff Base Ligands Containing Azo-Groups on $\mathrm{TiO}_{2}$. J. Korean Chem. Soc., 62, 328-332.

[2] Sato, H., Beppu, I., Haraguchi, T., Akitsu, T., Parida, R., Giri, S., Roymahaptra, G. and Joe, I.H. (2018) Optical Properties of Chiral Schiff Base Mn (II), Co (II), Ni (II) Complexes Having Azobenzene. J. Indian Chem. Soc., 95, 1487-1495.

[3] Oshima, M., Matsuno, M., Tsutsumi, Y., Sunaga, N., Haraguchi, T. and Akitsu, T. (2017) Synthesis of Chiral Schiff Base Metal Complex Inducing CD and Elucidation of Structure of Adsorption on Surface of Gold Nanoparticles. International Journal of Organic Chemistry, 7, 153-170. https://doi.org/10.4236/ijoc.2017.72013

[4] Tsutsumi, Y., Sunaga, N., Haraguchi, T. and Akitsu, T. (2017) Induced CD Form Chiral Schiff Base Metal Complexes Involving Azo-Dye Groups to Gold Nanoparticles. J. Indian Chem. Soc., 94, 1163-1172.

[5] Sunaga, N., Haraguchi, T. and Akitsu, T. (2019) Orientation of Chiral Schiff Base Metal Complexes Involving Azo-Groups for Induced CD on Gold Nanoparticles by Polarized UV Light Irradiation. Symmetry, 11, 1094. https://doi.org/10.3390/sym11091094

[6] Hu, T. and Desai, J.P. (2004) Soft-Tissue Material Properties under Large Deforma- 
tion: Strain Rate Effect. Proceedings of the 26th Annual International Conference of the IEEE EMBS, San Francisco, 1-5 September 2004, 2758-2761.

[7] Wu, W.-Y., Hsu, C.-F., Wu, M.-J., Chen, C.-N. and Huang, J.-J. (2017) $\mathrm{Ag}^{-\mathrm{TiO}_{2}}$ Composite Photoelectrode for Dye-Sensitized Solar Cell. Applied Physics A, 123, Article No. 357. https://doi.org/10.1007/s00339-017-0963-9

[8] Gaussian09. https://gaussian.com/

[9] Abadeer, N.S., Brennan, M.R., Wilson, W.L. and Murphy, C.J. (2014) Distance and Plasmon Wavelength Dependent Fluorescence of Molecules Bound to Silica-Coated Gold Nanorods. ACS Nano, 8, 8392-8406. https://doi.org/10.1021/nn502887j 